\title{
Efeito Residual de Herbicidas em Pré-Plantio do Feijoeiro, em Dois Sistemas de Aplicação em Plantio Direto e sua Viabilidade ECONÔMICA ${ }^{1}$
}

\author{
Economic Viability of Residual Herbicides in Dry Bean Pre-Planting under Two \\ Aplication Methods
}

COBUCCI, T. ${ }^{2}$, PORTELA, C.M.O. ${ }^{3}$, SILVA, W. ${ }^{4}$ e NETO MONTEIRO, A. ${ }^{5}$

\begin{abstract}
RESUMO - A pesquisa teve como objetivo avaliar a eficiência e a viabilidade econômica de controle de plantas daninhas com alguns herbicidas residuais (registrados ou não), aplicados em pré-plantio na cultura do feijoeiro. O experimento foi realizado em Santo Antônio de Goiás, no ano agrícola de 1999/2000. Os herbicidas foram aplicados em cobertura das plantas daninhas Commelina benghalensis e Bidens pilosa, com $3 \mathrm{t} \mathrm{ha}^{-1}$ de biomassa seca. Os tratamentos foram constituídos do fatorial $2 \times 10 \times 3$, arranjados em parcelas subsubdivididas no delineamento de blocos ao acaso, com três repetições; o primeiro fator consistiu de sistemas de dessecação da área [Sistema Integrado de Controle (SIC) e Aplique e Plante]. No SIC foi usado o sulfosate $\left(720 \mathrm{~g} \mathrm{ha}^{-1}\right)$ aos 20 dias antes do plantio e paraquat (200 $\left.\mathrm{g} \mathrm{ha}^{-1}\right)$ adicionado aos herbicidas com efeitos residuais, aplicados imediatamente após o plantio do feijoeiro. No sistema Aplique e Plante foi aplicado o sulfosate (720 $\left.\mathrm{g} \mathrm{ha}^{-1}\right)$ adicionado aos residuais, cinco dias antes do plantio do feijoeiro. O segundo fator representa a aplicação dos herbicidas com efeitos residuais, em $\mathrm{g} \mathrm{ha}^{-1}$ : sulfentrazone (200 e 300), dimethenamid (900 e 1.125), clomazone (360), pendimethalin (2.500), s-metolachlor (768 e 1.152), diclosulan $(12,45)$ e testemunha; e o terceiro, as doses dos herbicidas de pós-emergência: imazamox (15) + bentazon (240), imazamox (30) + bentazon (480) e testemunha. Os herbicidas residuais aplicados nos sistemas SIC e Aplique e Plante reduziram o crescimento inicial de Bidens pilosa. Para Euphorbia heterophylla somente os herbicidas diclosulan e sulfentrazone proporcionaram efeito semelhante. A aplicação de herbicidas residuais em pré-plantio mostrou ser viável economicamente, em virtude da redução dos de pós-emergência, exceto para os herbicidas dimethenamid e s-metolachlor.
\end{abstract}

Palavras-chave: Phaseolus vulgaris, pré-emergência e pós-emergência.

\begin{abstract}
The objective of this study was to evaluate the efficiency and economic viability of controlling weeds with residual herbicides, applied in pre-planting of common beans. The study was conducted in Santo Antônio de Goiás, Brazil, in 1999/2000 on three tha ${ }^{-1}$ of dry biomass. The 60 treatments were applied on the top of the weed plants (Commelina benghalensis and Bidens pilosa) disposed as a $2 \times 10 \times 3$ factorial, with split-plots in a randomized complete block design with three replicates. The first factor consisted of the desiccation systems in the area (Integrated Control System (ICS) and Apply and Sow). ICS consisted of sulfosate ( $720 \mathrm{~g} \mathrm{ha}^{-1}$ ) applied 20 days before planting and paraquat $200 \mathrm{~g} \mathrm{ha}^{-1}$ added to the residual herbicides and applied immediately after sowing. Apply and Sow consisted of (sulfosate $720 \mathrm{~g} \mathrm{ha}^{-1}$ ) added to the residual herbicides, applied five days before sowing. The second factor consisted of the residual herbicides applied in $\mathrm{g} \mathrm{ha} \mathrm{h}^{-1}$, sulfentrazone (200 and 300), dimethenamid (900 and 1.125); clomazone (360); pendimethalin (2.500), s-metolachlor (768 and 1152), diclosulan (12,45) and check; and the third factor consisted
\end{abstract}

Recebido para publicação em 1.10.2002 e na forma revisada em 17.12.2004.

Pesquisador, D.S., Embrapa Arroz e Feijão, Caixa Postal 179, 75375-000 Santo Antônio de Goiás-GO. ${ }^{3}$ Mestrando em Agronomia, Universidade Federal de Goiás, Caixa Postal 131, 74001-970 Goiânia-GO. ${ }^{4}$ Pesquisador, D.S., Embrapa Arroz e Feijão/CNPq Bolsista, Caixa Postal 179, 75375-000 Santo Antônio de Goiás-GO. ${ }^{5}$ Técnico Agrícola, Embrapa Arroz e Feijão/ BASF, Caixa Postal 179, 75375-000 Santo Antônio de Goiás-GO. 
of the doses of the post-emergence herbicides: imazamox (15) + bentazon (240), imazamox (30) + bentazon (480) and the check. The results showed that the residual herbicides applied in the ICS and Apply and Plant systems reduced the initial growth of Bidens pilosa, but only the herbicides diclosulan and sulfentrazone showed the same effect on Euphorbia heterophylla. The use of residual herbicides in pre-planting was economically viable reducing the amount of herbicides applied in pre-emergence, except for dimethenamid and s-metolachlor.

Key words: Phaseolus vulgaris, herbicides, pre emergence, post-emergence.

\section{INTRODUÇÃO}

O sistema plantio direto (SPD) constitui-se num dos mais importantes sistemas agrícolas de conservação de solo, por se destacar a semeadura em solo não-revolvido, na qual a semente é colocada em sulcos ou covas, com largura e profundidade suficientes para a adequada cobertura e contato delas com o solo. Ainda, pode-se fazer a semeadura direta sobre palhas ou coberturas mortas de vegetais. De acordo com Wagner-Riddle et al. (1994), essa prática conservacionista proporciona efeitos positivos em relação à redução da erosão, ao aumento da quantidade de água armazenada no solo e ao melhor controle de plantas daninhas; por sua vez, esse controle depende da quantidade da cobertura morta e do período em que essa quantidade persiste sobre a superfície do solo.

No plantio direto, o efeito alelopático da cobertura morta é mais intenso quanto maior a quantidade de matéria seca produzida. Por isso, nesse sistema há maior inibição da germinação das sementes de algumas espécies invasoras no solo que no sistema convencional (Almeida \& Rodrigues, 1985). Também a maior persistência da cobertura sobre o solo acarretará melhores e mais duradouros efeitos alelopáticos no controle das plantas daninhas.

A cobertura morta reduz a densidade da população de plantas daninhas (Prihar et al., 1975; Marochi et al., 1995; Sá Pereira et al., 1995), mas, mesmo com a sua redução, são necessárias medidas de controle, principalmente com o uso de herbicidas (Prihar et al., 1975).

Alguns herbicidas residuais têm comportamentos diferentes quando utilizados em pré-emergência sobre a cobertura morta, no sistema de plantio direto. Ao serem aplicados, eles deveriam chegar até a superfície do solo. Todavia, uma parte deles é retida pela cobertura, não atingindo o solo. Baumann (1977) observou que 30\% de atrazine não chega ao solo quando aplicada em cobertura de centeio.

Alguns herbicidas são mais lixiviados através das coberturas mortas que outros. A lixiviação para o solo de produtos residuais aplicados sobre cobertura morta depende da quantidade e do tipo de cobertura morta, do produto e de sua lavagem após a aplicação. Banks \& Robinson (1982) constataram que a aplicação do metribuzin sobre $8.900 \mathrm{~kg} \mathrm{ha}{ }^{-1}$ de palhada de trigo, seguida de irrigação com $8 \mathrm{~mm}$ de água, proporcionou $56 \%$ de lixiviado desse produto, no dia da aplicação. No entanto, o metolachlor $\left(2,88 \mathrm{~kg} \mathrm{ha}^{-1}\right)$ aplicado sobre $2.466 \mathrm{~kg} \mathrm{ha}^{-1}$ de palha de trigo, na cultura da soja, em plantio direto, não propiciou lixiviado do herbicida, mesmo recebendo imediatamente após a sua aplicação uma irrigação de $30 \mathrm{~mm}$ (Rodrigues \& Almeida, 1986). O clomazone também foi fortemente adsorvido à palha de trigo, mesmo com a ocorrência de chuva $(20 \mathrm{~mm})$ imediatamente após a aplicação. Fornarolli et al. (1997) concluíram que $85 \%$ de atrazine foi retida pela cobertura morta de aveia-preta e que, após a irrigação de $20 \mathrm{~mm}$, praticamente todo o atrazine foi lixiviado para o solo.

O objetivo deste trabalho foi avaliar a eficiência de controle de plantas daninhas e a viabilidade econômica de alguns herbicidas com efeitos residuais (registrados ou não), aplicados no Sistema Integrado de Controle (SIC) e no sistema Aplique e Plante, em pré-emergência na cultura do feijoeiro. 


\section{MATERIAL E MÉTODOS}

O experimento foi realizado em Santo Antônio de Goiás, no ano agrícola de 1999/ 2000. As características químicas e físicas do solo do local são apresentadas na Tabela 1. Os herbicidas foram aplicados em área com cobertura morta contendo aproximadamente $3 \mathrm{t} \mathrm{ha}^{-1}$ de Commelina benghalensis e Bidens pilosa. Os tratamentos foram constituídos do fatorial $2 \times 10 \times 3$, arranjados em parcelas subsubdivididas no delineamento de blocos ao acaso, com três repetições. $\mathrm{O}$ primeiro fator constituiu-se de sistemas de dessecação da área: Sistema Integrado de Controle (SIC) e Aplique e Plante. O SIC consistiu da aplicação de sulfosate $\left(720 \mathrm{~g} \mathrm{ha}^{-1}\right)$ aos 20 dias antes do plantio e de paraquat $\left(200 \mathrm{~g} \mathrm{ha}^{-1}\right)$ misturado aos herbicidas residuais e aplicados imediatamente após o plantio do feijoeiro. O Sistema Aplique e Plante consistiu da aplicação de sulfosate $\left(720 \mathrm{~g} \mathrm{ha}^{-1}\right)$ misturado aos residuais e aplicado cinco dias antes do plantio do feijoeiro. O segundo fator foi composto pelos herbicidas residuais aplicados, em $\mathrm{g} \mathrm{ha}^{-1}$, como sulfentrazone (200 e 300), dimethenamid (900 e 1.125), clomazone (360), pendimethalin (2.500), s-metolachlor (768 e 1.152), diclosulan $(12,45)$ e testemunha. Esses herbicidas foram aplicados nas subparcelas. O terceiro fator consistiu das doses dos herbicidas em pósemergência: imazamox (15) + bentazon (240) (meia dose), imazamox (30) + bentazon (480) (1 cheia) e a testemunha, distribuídos nas subsubparcelas. O tamanho das subparcelas e o das subsubparcelas foram, respectivamente, de 432 e $216 \mathrm{~m}^{2}$.

O feijoeiro, cultivar Pérola, foi semeado em $3 / 5 / 2000$, no espaçamento entre linhas de $0,50 \mathrm{~m}$ e com 16 sementes por metro, a uma profundidade média de $0,05 \mathrm{~m}$. A adubação no sulco de plantio foi realizada com $400 \mathrm{~kg} \mathrm{ha}^{-1}$ da fórmula 4:30:16 + Zn, com complementação de duas aplicações em cobertura de $150 \mathrm{~kg} \mathrm{ha}^{-1}$ de sulfato de amônio, aos 20 e 30 DAE (dias após a emergência). Os herbicidas de pósemergência foram aplicadas 25 dias depois do plantio do feijoeiro.

Os herbicidas foram aplicados com pulverizador costal pressurizado com $\mathrm{CO}_{2}$, equipado com barra de quatro bicos $110015^{2} \mathrm{DG}$, espaçados de $0,50 \mathrm{~m}$, totalizando 2,0 $\mathrm{m}$ de largura
Tabela 1 - Características químicas e físicas das amostras de solo no local do experimento, à profundidade de $0,10 \mathrm{~m}$. Santo Antônio de Goiás-GO, 2000

\begin{tabular}{|c|c|c|c|c|c|c|}
\hline \multirow{2}{*}{ Local } & \multirow{2}{*}{$\mathrm{pH}$} & \multirow{2}{*}{$\begin{array}{l}\text { M.O. } \\
\left(\mathrm{g} \mathrm{kg}^{-1}\right)\end{array}$} & \multirow{2}{*}{$\begin{array}{c}\text { CTC } \\
\left(\mathrm{cmol}_{\mathrm{c}} \mathrm{kg}^{-1}\right)\end{array}$} & Argila & Silte & Areia \\
\hline & & & & \multicolumn{3}{|c|}{$\left(\mathrm{g} \mathrm{kg}^{-1}\right)$} \\
\hline $\begin{array}{l}\text { Santo Antônio de } \\
\text { Goiás }\end{array}$ & 5,4 & 21 & 7,98 & 430 & 215 & 355 \\
\hline
\end{tabular}

efetiva. A pressão utilizada foi de $270 \mathrm{kPa}$, e o volume de calda, de $200 \mathrm{~L} \mathrm{ha}^{-1}$.

Foram realizadas contagens do número de plantas $\mathrm{m}^{-2}$, juntamente com contagens do número de folhas no estádio de crescimento de $B$. pilosa e E. heterophylla, que variou na escala de 0 a 4 folhas e superior a 4 folhas. O número total de folhas das duas plantas daninhas se originou da soma desses dois estádios de crescimento, presentes na área experimental, aos 25 dias após o plantio do feijoeiro (antes da aplicação dos tratamentos de pós-emergência). O efeito dos herbicidas de pós-emergência sobre a cultura foi avaliado aos 21 dias após a aplicação (DAA), de acordo com os sintomas de intoxicação visual, numa escala de 0 a $100 \%$, em que 0 equivale a nenhum dano visivel na planta e 100, à morte desta (Frans, 1972). As avaliações da eficiência agronômica, também feitas aos 21 DAA, foram efetuadas de forma visual, empregando-se uma escala em que $0 \%$ representou nenhum controle e $100 \%$, o maior controle em comparação à testemunha.

O rendimento de grãos foi avaliado em $8 \mathrm{~m}^{2}$ de área colhida e a umidade corrigida para $13 \%$. A relação entre beneficio e custo (mão-de-obra e herbicidas) foi calculada da seguinte maneira: beneficio [produtividade do feijoeiro $\left(\mathrm{kg} \mathrm{ha}^{-1}\right) \mathrm{x}$ preço do feijão (US\$23,08 a saca de $60 \mathrm{~kg})$ ]; e custo [(custo de produção de US\$ 692,31 $\mathrm{ha}^{-1}$ ) + (custo dos tratamentos com herbicidas)]. Consideraram-se como custo de aplicação o valor de US\$ 7,69 ha ${ }^{-1}$ e, como custo de cada herbicida, os valores obtidos (em US\$) no mercado de Goiânia em dezembro de 2000, ou seja: Zapp (sulfosate) - 7,31 L-1; Gramoxone (paraquat) - 12,54 L L ; Zeta 900 (dimethenamid) - 23,08 L $\mathrm{L}^{-1}$; Boral (sulfentrazone) - 51,54 L-1; Gamit 360 CS (clomazone) - 33,85 L-1 ; Herbadox 500 (pendimethalin) - 13,54 L $\mathrm{L}^{-1}$; Dual Gold (s-metolachlor) - 21,15 L $\mathrm{L}^{-1}$; Basagran (bentazon) $-31,54 \mathrm{~L}^{-1}$; e Sweeper (imazamox) - 1,65 g ${ }^{-1}$. 
Os dados de controle de B. pilosa e $E$. heterophylla, rendimentos de grãos do feijão e os valores da relação benefício/custo (análise da viabilidade econômica) dos herbicidas residuais foram submetidos à análise de variância, a 5\% de probabilidade. As médias dos tratamentos foram comparadas com a da testemunha sem herbicidas, utilizando-se o teste de Dunnett a 5\% de probabilidade. Em cada dose de herbicida aplicada em pósemergência, o sistema de dessecação foi testado por meio do teste $\mathrm{F}$ a $5 \%$ de probabilidade.

\section{RESULTADOS E DISCUSSÃO}

O número médio de plantas de $B$. pilosa e de E. heterophylla nos tratamentos sem herbicidas com efeitos residuais foi maior no sistema de dessecação Aplique e Plante que no SIC (Tabelas 2 e 3). Cobucci \& Portela (1999) e Skora Neto \& Marques (2000) constataram que herbicidas de dessecação, como glyphosate, aplicados 20 dias antes do plantio do feijoeiro favorecem a germinação das plantas daninhas até o plantio da cultura, tendo como conseqüência a eliminação do primeiro fluxo de invasoras, com a primeira aplicação com glyphosate. Em muitos casos, a segunda aplicação feita com paraquat após o plantio tem propiciado diminuição ou eliminação dos herbicidas de pós-emergência.

Quanto à presença dos herbicidas com efeitos residuais nos sistemas de dessecação, observa-se, nas Tabelas 2 e 3, que $300 \mathrm{~g} \mathrm{ha}^{-1}$ de sulfentrazone, no sistema SIC (aplicação

Tabela 2 - Porcentagem média de controle de Bidens pilosa, aos 25 dias após o plantio do feijoeiro, em resposta aos herbicidas residuais nos sistemas SIC e Aplique e Plante. Santo Antônio de Goiás-GO, 2000

\begin{tabular}{|c|c|c|c|c|c|}
\hline \multirow{3}{*}{ Herbicida residual } & \multirow{3}{*}{$\begin{array}{c}\text { Dose } \\
\left(\mathrm{g} \mathrm{ha}^{-1}\right)\end{array}$} & \multicolumn{2}{|c|}{ SIC } & \multicolumn{2}{|c|}{ Aplique e Plante } \\
\hline & & $>4$ folhas & Total & $>4$ folhas & Total \\
\hline & & \multicolumn{2}{|c|}{$(\%$ de controle $)$} & \multicolumn{2}{|c|}{$(\%$ de controle $)$} \\
\hline sulfentrazone & 200 & 0 & 16 & 34 & 45 \\
\hline sulfentrazone & 300 & 86 & 64 & 59 & 72 \\
\hline dimethenamid & 900 & 0 & 0 & 34 & 42 \\
\hline dimethenamid & 1.125 & 57 & 9 & 0 & 18 \\
\hline clomazone & 360 & 90 & 62 & 78 & 36 \\
\hline pendimethalin & 2.500 & 86 & 14 & 60 & 60 \\
\hline s-metolachlor & 768 & 24 & 53 & 0 & 15 \\
\hline s-metolachlor & 1.152 & 43 & 58 & 84 & 54 \\
\hline diclosulan & 12,45 & 100 & 75 & 59 & 71 \\
\hline Sem herbicida residual ${ }^{1 /}$ & - & 21 & 288 & 32 & 399 \\
\hline
\end{tabular}

${ }^{1 /}$ Número médio de B. pilosa na testemunha nos sistemas SIC e Aplique e Plante.

Tabela 3 - Porcentagem média de controle de Euphorbia heterophylla, aos 25 dias após o plantio do feijoeiro, em resposta aos herbicidas residuais nos sistemas SIC e Aplique e Plante. Santo Antônio de Goiás-GO, 2000

\begin{tabular}{|c|c|c|c|c|c|}
\hline \multirow{3}{*}{ Herbicida residual } & \multirow{3}{*}{$\begin{array}{c}\text { Dose } \\
\left(\mathrm{g} \mathrm{ha}^{-1}\right)\end{array}$} & \multicolumn{2}{|c|}{$\mathrm{SIC}$} & \multicolumn{2}{|c|}{ Aplique e Plante } \\
\hline & & $>4$ folhas & Total & $>4$ folhas & Total \\
\hline & & \multicolumn{2}{|c|}{$\%$ de controle } & \multicolumn{2}{|c|}{$\%$ de controle } \\
\hline sulfentrazone & 200 & 22 & 3 & 9 & 16 \\
\hline sulfentrazone & 300 & 43 & 22 & 1 & 23 \\
\hline dimethenamid & 900 & 0 & 0 & 0 & 9 \\
\hline dimethenamid & 1.125 & 6 & 0 & 0 & 0 \\
\hline clomazone & 360 & 0 & 0 & 1 & 7 \\
\hline pendimethalin & 2.500 & 0 & 0 & 0 & 20 \\
\hline S-metolachlor & 768 & 0 & 0 & 0 & 0 \\
\hline s-metolachlor & 1.152 & 0 & 0 & 0 & 0 \\
\hline diclosulan & 12,45 & 86 & 5 & 98 & 29 \\
\hline Sem herbicida residual ${ }^{1 /}$ & - & 75 & 305 & 85 & 384 \\
\hline
\end{tabular}

${ }^{1 /}$ Número médio de E. heterophylla na testemunha nos sistemas SIC e Aplique e Plante. 
associada ao paraquat após plantio do feijoeiro), proporcionaram, aos 25 dias após o plantio do feijoeiro, 64\% de controle total de B. pilosa e $21 \%$ de E. heterophylla, em relação ao tratamento sem herbicida residual. Esse controle de $B$. pilosa foi possível em virtude de o sulfentrazone lixiviar, em grande quantidade, da palha para o solo (Rodrigues et al., 1999). Outro fator importante é que, com a presença desse herbicida residual no solo, no sistema SIC, mesmo não proporcionando bom controle do total dessas plantas daninhas, ocorreu controle de $86 \%$ de $B$. pilosa e de $42 \%$ de $E$. heterophylla nos estádios mais avançados (mais de quatro folhas). O sulfentrazone retardou o crescimento das espécies invasoras proporcionando, assim, vantagem competitiva ao feijoeiro - e possibilitou o uso de menores doses dos herbicidas de pós-emergência. Observa-se nas Tabelas 2 e 3 que, no sistema Aplique e Plante o sulfentrazone também propiciou controle total das invasoras $(72 \%$ de B. pilosa e $23 \%$ de E. heterophylla), comprovando a lixiviação do herbicida através da cobertura verde (Cobucci et al., sd).

O diclosulan apresenta grande capacidade de passar pela cobertura (morta ou verde) e atingir o solo (Cobucci et al., sd), ou seja, este herbicida atingiu o solo e proporcionou controle de $71 \%$ do total de B. pilosa, tanto no sistema SIC quanto no Aplique e Plante. No estádio acima de quatro folhas, esse produto proporcionou $100 \%$ de controle de $B$. pilosa, no sistema SIC, e de 59\%, no Aplique e Plante (Tabelas 2 e 3). Ademais, o diclosulan propiciou controle superior a $86 \%$ de E. heterophylla, no estádio acima de quatro folhas, e baixo controle total dessa invasora. O efeito do diclosulan, bem como o do sulfentrazone, foi o de reduzir o crescimento inicial dessas espécies invasoras, reduzindo-lhes a capacidade competitiva. Nessa situação, há necessidade de menores doses de herbicidas em pós-emergência.

Com S-metolachlor e dimethenamid, o controle de $B$. pilosa e E. heterophylla não foi eficiente (Tabelas 2 e 3). Esses resultados eram esperados, pois esses herbicidas apresentam baixos niveis de controle dessas invasoras, mesmo quando aplicados em plantio convencional.

Clomazone e pendimethalin proporcionaram baixo controle total de $B$. pilosa e E. heterophylla; entretanto, para B. pilosa, verificou-se que houve controle variando de 60 a 90\% no estádio acima de quatro folhas, considerando os dois sistemas (Tabelas 2 e 3). Isso mostra que, nessa fase de desenvolvimento das plantas daninhas, esses herbicidas propiciaram efeito negativo no desenvolvimento inicial delas e, conseqüentemente, favoreceram o desenvolvimento do feijoeiro.

As porcentagens de controle de $B$. pilosa e E. heterophylla aos 21 dias após a aplicação dos herbicidas de pós-emergência são apresentadas na Tabela 4. Observa-se que, em cada tratamento de pós-emergência, a média de controle das invasoras no sistema SIC foi maior que no Aplique e Plante. A superioridade de controle do sistema SIC, em comparação ao sistema Aplique e Plante, pode ser devido ao menor número de plantas daninhas e também ao menor estádio de crescimento e desenvolvimento delas.

A mistura de diclosulan mais paraquat, no sistema SIC, e de diclosulan com o sulfosate, no sistema Aplique e Plante, proporcionou excelente controle das invasoras, mesmo sem a aplicação do herbicida aplicado em pósemergência, em relação ao tratamento sem herbicida residual (Tabela 4).

No "fechamento" da cultura do feijoeiro, os niveis de fitoxicidade referentes aos tratamentos com herbicidas foram insignificantes e, conseqüentemente, não são apresentados. Devido a isso, as produtividades correlacionaram-se diretamente com os niveis de controle das plantas daninhas (Tabela 5).

O diclosulan, por ter propiciado bom controle das invasoras na dose de $12,45 \mathrm{~g} \mathrm{ha}^{-1}$ (Tabelas 2 e 3) e pelo fato de lixiviar com grande facilidade da cobertura seca ou verde para o solo (Cobucci et al., sd), apresentou excelente relação benefício/custo, no sistema Aplique e Plante, em ausência da aplicação de pós-emergência, sendo, portanto, um produto com boas perspectivas para essa modalidade de uso. Entretanto, em virtude dos possiveis problemas de toxicidade à cultura, da persistência no solo (meia-vida de 33 a 65 dias) e de ainda o diclosulan não ser liberado para utilização no feijoeiro pelo Ministério da Agricultura, pesquisas complementares deverão ser realizadas antes de se recomendar o produto para essa cultura. Para isso, devem ser avaliadas doses e fitotoxicidade em diferentes cultivares. 
Tabela 4 - Porcentagem média de controle de Bidens pilosa e Euphorbia heterophylla, aos 21 dias após aplicação dos herbicidas pósemergência. Santo Antônio de Goiás-GO, 2000

\begin{tabular}{|c|c|c|c|c|c|c|c|}
\hline \multirow{3}{*}{ Herbicida } & \multirow{3}{*}{$\begin{array}{c}\text { Dose } \\
\left(\mathrm{g} \mathrm{ha}^{-1}\right)\end{array}$} & \multicolumn{6}{|c|}{ Pós-emergência ${ }^{1 /}$} \\
\hline & & \multicolumn{2}{|c|}{0 dose } & \multicolumn{2}{|c|}{$1 / 2$ dose } & \multicolumn{2}{|c|}{1 dose } \\
\hline & & SIC & Aplique e Plante & SIC & Aplique e Plante & SIC & Aplique e Plante \\
\hline testemunha & - & $0 \mathrm{a}$ & $0 \mathrm{a}$ & $79 \mathrm{a}$ & $62 \mathrm{~b}$ & $80 \mathrm{a}$ & $63 \mathrm{~b}$ \\
\hline sulfentrazone & 200 & $30 * a$ & $0 \mathrm{~b}$ & $88 * a$ & $73 * b$ & $96 * a$ & $79 * b$ \\
\hline sulfentrazone & 300 & $63 * a$ & $0 \mathrm{~b}$ & $97 * a$ & $76 * b$ & $99 * a$ & $83 * b$ \\
\hline dimethenamid & 900 & $0 \mathrm{a}$ & $0 \mathrm{a}$ & $74 \mathrm{a}$ & $63 \mathrm{~b}$ & $78 \mathrm{a}$ & $75 * a$ \\
\hline dimethenamid & 1.125 & $7 * a$ & $0 \mathrm{~b}$ & $78 \mathrm{a}$ & $60 \mathrm{~b}$ & $83 \mathrm{a}$ & $75 * b$ \\
\hline clomazone & 360 & $15 * a$ & $0 \mathrm{~b}$ & $82 \mathrm{a}$ & $67 \mathrm{~b}$ & $90 \mathrm{a}$ & $80 * b$ \\
\hline pendimethalin & 2.500 & $10 * a$ & $0 \mathrm{~b}$ & $81 \mathrm{a}$ & $63 \mathrm{~b}$ & $87 * a$ & $69 * b$ \\
\hline s-metolaclhor & 768 & $0 \mathrm{a}$ & $0 \mathrm{a}$ & $70 \mathrm{a}$ & $72 * a$ & $80 \mathrm{a}$ & $82 * a$ \\
\hline s-metolaclhor & 1.152 & $5 * a$ & $0 \mathrm{~b}$ & $80 \mathrm{a}$ & $72 * b$ & $88 * a$ & $78 * b$ \\
\hline diclosulan & 12,45 & $91 * a$ & $96 * a$ & $97 * a$ & $100 * a$ & $97 * a$ & $99 * a$ \\
\hline Média & - & $22,1 \mathrm{a}$ & $9,6 \mathrm{~b}$ & $82,6 \mathrm{a}$ & $70,8 \mathrm{~b}$ & $87,5 \mathrm{a}$ & $78,3 \mathrm{~b}$ \\
\hline
\end{tabular}

1/ Aplicação, em g ha ${ }^{-1}$, de imazamox (15) + bentazon (240) (1/2 dose), imazamox (30) + bentazon (480) (1 dose).

Em cada herbicida residual e cada dose de herbicida aplicada em pós-emergência e sistema de dessecação (linha), a difere de b pelo teste $\mathrm{F}(\mathrm{P}<0,05)$.

* Estatisticamente diferente da testemunha pelo teste de Dunnett $(\mathrm{P}<0,05)$.

Tabela 5 - Rendimento médio de grãos de feijão $\left(\mathrm{kg} \mathrm{ha}^{-1}\right)$, em resposta aos herbicidas. Santo Antônio de Goiás-GO, 2000

\begin{tabular}{|c|c|c|c|c|c|c|c|}
\hline \multirow{3}{*}{ Herbicida } & \multirow{3}{*}{$\begin{array}{c}\text { Dose } \\
\left(\mathrm{g} \mathrm{ha}^{-1}\right)\end{array}$} & \multicolumn{6}{|c|}{ Pós-emergência ${ }^{1 /}$} \\
\hline & & \multicolumn{2}{|c|}{0 dose } & \multicolumn{2}{|c|}{$1 / 2$ dose } & \multicolumn{2}{|c|}{1 dose } \\
\hline & & SIC & Aplique e Plante & SIC & Aplique e Plante & SIC & Aplique e Plante \\
\hline testemunha & - & 1.081 & 811 & 2.056 & 1.614 & 2.325 & 1.653 \\
\hline sulfentrazone & 200 & 1.427 & 873 & 2.924 & $2.089^{*}$ & 2.753 & 1.899 \\
\hline sulfentrazone & 300 & $2.196^{*}$ & 1.333 & 3.344 & $2.346^{*}$ & $3.174 *$ & 2.475 \\
\hline dimethenamid & 900 & 1.344 & 1.124 & 1.931 & 1.677 & 1.535 & 2.942 \\
\hline dimethenamid & 1.125 & 1.496 & 1.171 & 2.288 & $2.131^{*}$ & 2.245 & 2.269 \\
\hline clomazone & 360 & 1.681 & 1.716 & 2.821 & 1.685 & $2.929^{*}$ & 2.311 \\
\hline pendimethalin & 2.500 & 1.572 & 1.080 & 2.880 & $1887^{*}$ & $2.981 *$ & 2.366 \\
\hline s-metolaclhor & 768 & 923 & 876 & 1.829 & $1.954^{*}$ & 2.484 & 2.658 \\
\hline s-metolaclhor & 1.152 & 1.126 & 1.103 & 2.353 & $2.207^{*}$ & 2.719 & 2.844 \\
\hline diclosulan & 12,45 & $2.966^{*}$ & $3.066^{*}$ & 2.928 & $3071^{*}$ & $2.913^{*}$ & 2.826 \\
\hline
\end{tabular}

1/ Aplicação, em g ha ${ }^{-1}$, de imazamox (15) + bentazon (240) (1/2 dose), imazamox (30) + bentazon (480) (1 dose).

* Estatisticamente diferente da testemunha pelo teste de Dunnett $(\mathrm{P}<0,05)$.

Sulfentrazone na dose de $300 \mathrm{~g} \mathrm{ha}^{-1}$ também propiciou excelente relação benefício/ custo no sistema SIC com a complementação de meia dose de herbicidas aplicados em pósemergência. No sistema Aplique e Plante houve redução do produto lixiviado para o solo (Cobucci et al., sd), o que resultou em menor controle das invasoras, diminuindo assim a relação benefício/custo. Esse produto também apresenta possibilidade de emprego em dessecantes de área (sistema SIC), porém devem ser estudadas doses e toxicidade em diferentes cultivares de feijão.
Pedimenthalin e clomazone também apresentaram aumento na relação benefício/ custo em comparação com o tratamento testemunha (Tabela 6), porém os melhores valores da relação foram obtidos no sistema SIC e com a aplicação adicional dos herbicidas em pósemergência (meia dose ou uma dose).

O dimethenamid não apresentou boa relação benefício/custo e igualou-se à testemunha (sem herbicida residual). Isso foi devido aos baixos níveis de controle que esse produto proporcionou a $E$. heterophylla e B. pilosa. Entretanto, Cobucci et al. (sd) 
Tabela 6 - Valor médio da relação benefício/custo (análise da viabilidade econômica) dos herbicidas residuais Santo Antônio de Goiás-GO, 2000

\begin{tabular}{|c|c|c|c|c|c|c|c|c|}
\hline \multirow{3}{*}{ Herbicida residual } & \multirow{3}{*}{$\begin{array}{c}\text { Dose } \\
\left(\mathrm{g} \mathrm{ha}^{-1}\right)\end{array}$} & \multicolumn{6}{|c|}{ Pós-emergência ${ }^{1 /}$} & \multirow{3}{*}{ Média } \\
\hline & & \multicolumn{2}{|r|}{0 dose } & \multicolumn{2}{|c|}{$1 / 2$ dose } & \multicolumn{2}{|r|}{1 dose } & \\
\hline & & SIC & Aplique e Plante & SIC & Aplique e Plante & SIC & Aplique e Plante & \\
\hline testemunha & - & $0,57^{2}$ & 0,44 & 1,03 & 0,83 & $1,13^{*}$ & 0,82 & 0,80 \\
\hline sulfentrazone & 200 & 0,73 & 0,46 & 1,43 & $1,05^{*}$ & $1,3^{*}$ & 0,92 & 0,98 \\
\hline sulfentrazone & 300 & $1,10^{*}$ & 0,69 & 1,46 & $1,16^{*}$ & $1,44 *$ & 1,18 & $1,16^{*}$ \\
\hline dimethenamid & 900 & 0,68 & 0,59 & 0,94 & 0,84 & 0,72 & 0,94 & 0,78 \\
\hline dimethenamid & 1.125 & 0,75 & 0,61 & 1,10 & $1,05^{*}$ & $1,05^{*}$ & 1,09 & 0,94 \\
\hline clomazone & 360 & 0,84 & 0,88 & 1,35 & 0,83 & $1,36^{*}$ & 1,10 & $1,06^{*}$ \\
\hline pendimethalin & 2.500 & 0,79 & 0,56 & 1,38 & $0,93 *$ & $1,38 *$ & 1,13 & 1,02 \\
\hline s-metolachlor & 768 & 0,47 & 0,46 & 0,90 & $0,98 *$ & $1,18^{*}$ & 1,29 & 0,88 \\
\hline s-metolachlor & 1.152 & 0,57 & 0,58 & 1,15 & $1,10^{*}$ & $1,28 *$ & 1,38 & 1,01 \\
\hline diclosulan & 12,45 & $1,54^{*}$ & $1,61^{*}$ & 1,45 & $1,55^{*}$ & $1,40^{*}$ & 1,38 & $1,55^{*} \mathrm{~A}$ \\
\hline
\end{tabular}

${ }^{1 /}$ Aplicação, em g ha ${ }^{-1}$, de imazamox (15) + bentazon (240) (1/2dose), imazamox (30) + bentazon (480) (1 dose).

* Estatisticamente diferente da testemunha pelo teste de Dunnett $(\mathrm{P}<0,05)$.

observaram que cerca de $50 \%$ do herbicida deixa de atingir o solo com aproximadamente $10 \mathrm{t} \mathrm{ha}^{-1}$ de cobertura morta e poderá ser viável para espécies suscetiveis, juntamente com os herbicidas dessecantes (no sistema SIC), dependendo da qualidade de cobertura.

A dose de $1.152 \mathrm{~g} \mathrm{ha}^{-1}$ de S-metolachlor aumentou a relação beneficio/custo em comparação à testemunha (Tabela 6). Os melhores valores da relação foram obtidos com a utilização dos herbicidas de pós-emergência (uma dose).

A aplicação de herbicidas com efeito residual em mistura com glyphosate e/ou paraquat na dessecação de área, em plantio direto do feijoeiro, reduz o crescimento inicial das plantas daninhas e é uma prática viável, desde que esses herbicidas sejam lixiviados através da cobertura para o solo, e também levando em consideração a seletividade dos herbicidas às plantas daninhas e ao feijoeiro, do período de persistência dos herbicidas no solo e da umidade do solo.

\section{LITERATURA CITADA}

ALMEIDA, S. F.; RODRIGUES, B. N. Guia do herbicida: contribuição para o uso adequado e plantio direto e convencional. Londrina: IAPAR, 1985. 482 p.

BANKS, P. A.; ROBINSON, E. L. The influence of straw mulch on the soil reception and persistence of metribuzin. Weed Sci., v. 30, n. 2, p. 164-168, 1982.
BAUMANN, T. T. Amount and persistence of atrazine in soil with three tillage systems. Dis. Abstr. Ins., v. 37, n. 10, p. 4794-4795, 1977.

COBUCCI, T.; PORTELA, C. M. O. Aplicação seqüencial de herbicidas aplicados em pré-plantio no controle de plantas daninhas, na cultura do feijoeiro. In: REUNIÃO NACIONAL DE PESQUISA DE FEIJÃO, 6., 1999, Salvador. Resumos Expandidos... Santo Antônio de Goiás: Embrapa Arroz e Feijão, 1999. p. 465-468.

COBUCCI, T. et al. Comportamento de herbicidas com efeito residual em diferentes coberturas na cultura do feijoeiro. Planta Daninha, (no prelo).

FORNAROLLI, D. A.; RODRIGUES, B. N.; VALÉRIO, M. A. Influência da cobertura morta no comportamento do herbicida atrazine. In: CONGRESSO BRASILEIRO DA CIÊNCIA DAS PLANTAS DANINHAS, 21., 1997, Caxambu. Resumos... Caxambu: SBCPD, 1997. p. 343.

FRANS, R. W. Measuring plant response. In: WILKINSON, R. E. (Ed.) Research methods in weed science. Puerto Rico: Weed Science Society of America, 1972. p. 28-41.

MAROCHI, A. I.; MIERLO, C. V.; GALLO, P. Eficiência de flumetsulam aplicado sob diferentes quantidades de palha, em sistema de plantio direto, no controle de dicotiledôneas na cultura da soja. In: CONGRESSO BRASILEIRO DA CIÊNCIA DAS PLANTAS DANINHAS, 20., Florianópolis, 1995. Resumos... Florianópolis: SBCPD, 1995. p. 76-78.

PRIHAR, S. S.; SANDHU, K. S.; KHERA, K. L. Maize (Zea mays L.) and weed growth as affected by levels of straw mulching and without herbicides under conventional and minimum tillage. Ind. J. Ecol., v. 2, p. 13-22, 1975.

Planta Daninha, Viçosa-MG, v. 22, n. 4, p. 583-590, 2004 
RODRIGUES, B. N. Influência da cobertura morta no comportamento dos herbicidas imazaquin e clomazone. Planta Daninha, v. 11, n. 1/2, p. 21-28, 1993.

RODRIGUES, B. N. et al. Influência da cobertura morta no comportamento do herbicida sulfentrazone. Planta

Daninha, v. 17, n. 3, p. 445-458, 1999.

RODRIGUES, B. N.; ALMEIDA, F. S. Influência da cobertura morta no comportamento dos herbicidas atrazine e metolachlor no sistema plantio direto. In: IAPAR.

(Londrina, PR) Resultados de pesquisa da área de Herbologia, safras 1984/1985 e 1985/1986. Londrina: 1986. (Mimeografado).
SÁ PEREIRA, E. et al. Avaliações qualitativas e quantidades da comunidade infestante de plantas na cultura de soja (Glycine max), cultivada em plantio direto e convencional e submetida a distintos sistemas de controle das plantas daninhas. In: CONGRESSO BRASILEIRO DA CIÊNCIA DAS PLANTAS DANINHAS, 20., 1995, Florianópolis. Resumos... Florianópolis: SBCPD, 1995. p. 431-432.

SKORA NETO, F.; MARQUES, A. Avaliação de paraquat em aplicação seqüencial ao sulfosate na operação em plantio direto na cultura do feijão. In: CONGRESSO BRASILEIRO DA CIÊNCIA DAS PLANTAS DANINHAS, 22., 2000, Foz do Iguaçu. Resumos... Londrina: SBCPD, 2000. p. 236. 